\title{
O "Estado da Arte" da produção acadêmica sobre o fenômeno da judicialização da saúde no Brasil
}

The "State-of-the-Art" of the academic production on the phenomenon of health judicialization in Brazil

El "Estado del arte" de la producción académica sobre el fenómeno de la judicialización de la salud en Brasil

RESUMO. Introdução: a saúde é um tema muito estudado no Brasil, haja vista a grande quantidade de estudos nos campos da saúde pública, saúde coletiva, epidemiologia, bioética, dentre tantos outros. No entanto, o tema da saúde, como um direito, pode ser considerado uma temática recente. Metodologia: este trabalho realizou uma análise da produção acadêmica, entre os anos de 2010 e 2014 sobre judicialização da saúde, por meio de revisão de literatura, realizada em dois bancos de dados. Resultados: a produção acadêmica no Brasil tem se dedicado ao estudo do fenômeno da judicialização do direito à saúde, enquanto direito fundamental social constitucionalizado, por meio de duas correntes de pensamento distintas: uma que vê no ativismo político do judiciário um empecilho para a efetivação do direito à saúde, enquanto direito coletivo, e outra, que atribui a este fenômeno uma forma de ampliação da cidadania e fortalecimento da democracia. Conclusão: a produção acadêmica brasileira tem contribuído para a superação de uma visão polarizada sobre a judicialização da saúde e promove um avanço em um caminho de produção de um "saber-fazer" interdisciplinar e integrado.

Palavras-chave: Direito. Judicialização. Saúde.

ABSTRACT. Introduction: health is a widely researched topic in Brazil, considering the vast amount of studies in the fields of public health, collective health, epidemiology and bioethics, to name a few. Health as a right, however, can still be considered a recent topic. Methodology: this work performed, through literature review, an analysis of academic production between the years of 2010 and 2014 on the topic of judicialization of health, gathered from two databases. Results: academic production in Brazil is centered on the study of the phenomena of judicialization of the right to health as a social and constitutionalized fundamental right through two distinct schools of thought: one that sees on the political activism of the Judiciary branch a hindrance to the effective implementation of the right to health as a collective right, and other that ascribes to this phenomenon a way to widen citizenship rights and strengthen democracy. Conclusion: brazilian academic production has contributed to overcome a polarized view on the judicialization of health and represents a step towards the production of an interdisciplinary and integrated "know-how".

Keywords: Health. Law. Judicialization.

\footnotetext{
1 Técnica Especializada do Ministério da Saúde. Secretaria de Gestão Estratégica e Participativa, Departamento de Articulação Interfederativa - Distrito Federal - Brasília. Brasil. E-mail: guaraci.bittencourt@saude.gov.br.
} 
RESUME. Introducción: la salud es un tema muy estudiado en Brasil, dado el gran número de estudios en los campos de la salud pública, la salud colectiva, epidemiología, la bioética, entre muchos otros. Sin embargo, el tema de la salud como un derecho puede ser considerado un tema reciente. Metodología: en este estudio se llevó a cabo un análisis de la producción académica entre los años 2010 y 2014 sobre la " legalización de la salud " a través de revisión bibliográfica, realizada en dos bases de datos. Resultados: la producción académica en Brasil se ha dedicado al estudio de lo fenómeno de la judicialización del derecho a la salud, mientras un derecho social fundamental constitucionalizado, a través de dos escuelas distintas de pensamiento: una que ve el activismo político del poder judicial a la manera de un obstáculo para la realización del derecho a la salud, como un derecho colectivo, y la otra, que concede a este fenómeno una forma de expansión de la ciudadanía y el fortalecimiento de la democracia. Conclusión: la producción académica brasileña ha contribuido a la superación de una visión polarizada sobre la legalización de la salud y promueve el avanzo hacia la producción de un "saber-hacer" interdisciplinario e integrado.

Palabras-clave: Salud, Derecho, Judicialización.

\section{Introdução}

A saúde é um dos temas mais estudados no Brasil, haja vista a grande quantidade de estudos nos campos da saúde pública, saúde coletiva, epidemiologia, bioética, dentre tantos outros. No entanto, seu estudo como um direito pode ser considerada uma temática recente.

A Constituição de 1988 estruturou prestações estatais de forma inédita, em matéria de saúde, criando o Sistema Único de Saúde (SUS), com vistas a alcançar o nível máximo de garantia proporcionado pelo sistema jurídico. Pode-se afirmar, portanto, que a consagração do direito à saúde, como um direito passível de proteção e tutela pelo Estado se deu com a Constituição Federal de 1988.

O Direito à Saúde é um direito de cidadania, que implica em uma ação de proteção e prestações do Estado para alcançar o princípio constitucional da dignidade da pessoa humana. (1)

O fato de a Constituição Federal (2), em seu art. 196 afirmar que "a saúde é direito de todos e dever do Estado, garantido mediante políticas sociais e econômicas" e ter garantido, aos cidadãos brasileiros, a liberdade para reivindicar, via judicial, seus direitos constitucionalmente assegurados, em caso de lesão ou ameaça, gerou o que hoje comumente chamamos de 'judicialização da saúde'. 
É bem verdade que esta não é a única explicação, tampouco justificativa, para o recente e crescente fenômeno da 'judicialização da saúde'. O que estamos chamando de 'judicialização da saúde' é a avalanche de demandas judiciais, que se iniciou, ainda na década de 90, com o surgimento da AIDS (Acquired Immunodeficiency Syndrome) e suas demandas judiciais por medicamentos, que vem gerando consequências na gestão e financiamento do SUS e na relação entre os três Poderes - Executivo, Legislativo e Judiciário.

A Judicialização é um fenômeno político social, no sentido do alargamento das possibilidades de ação junto ao Poder Judiciário, e o aumento exponencial do número de demandas, de caráter individual, interpostas junto a esse poder, que versam sobre questões de saúde (3).

Partindo do entendimento de que a função precípua do setor acadêmico é gerar conhecimentos, ciência, tecnologia e inovação para o bem-estar da sociedade propôsse a realização de uma análise da produção acadêmica sobre 'judicialização da saúde', nos últimos cinco anos (2010-2014), no intuito de identificar o tema mais estudado e realizar uma análise crítica do principal ponto de convergência teórico.

\section{Evolução do conceito de saúde}

A concepção de que a saúde constitui um direito humano fundamental, passível de proteção e tutela estatal é resultado da evolução do conceito de saúde.

A primeira concepção de saúde está ligada a um pensamento mágico, no qual os povos primitivos viam o doente como vítima de demônios e espíritos malignos (4).

No século IV a.C., Hipócrates já associava a saúde da população à cidade em que viviam e seus hábitos (5). No século XVII, em sentido contrário, surgiu o conceito de saúde enquanto ausência de doença. O corpo humano foi equiparado à máquina, impondo um caráter mecanicista da doença, enquanto falha a ser resolvida (5).

O ambiente social do fim do século XIX e início do século XX, auge da Revolução Industrial, propiciou o debate entre as duas correntes de pensamento que buscavam conceituar a saúde. De um lado, a população marginalizada, que vivia em condições precárias impulsionava o entendimento de saúde como diretamente dependente de variáveis como meio ambiente, trabalho, alimentação e moradia. Por outro lado, o 
avanço da ciência e a descoberta de germes causadores de doença enfatizava a conceituação de saúde como ausência de doenças (5).

A Organização Mundial de Saúde, em 1946, em um mundo em processo de reorganização de seus pactos conceituou a saúde como: "estado de completo bem-estar físico, mental e social e não apenas a ausência de doença" (6). Esta noção superou a ideia de saúde como mera inexistência de doenças, destacando a importância de um equilíbrio interno e externo do homem.

\section{Saúde enquanto Direito Fundamental Social}

Os direitos sociais representaram uma mudança de paradigma no fenômeno do direito porque produziram uma modificação na postura do Estado, de abstencionista para um enfoque prestacional.

Essa mudança de paradigma teve seu início, ainda nos Séculos XVIII e XIX, e a luta da classe burguesa pelo reconhecimento de uma série de prerrogativas frente ao Estado, com o objetivo de concretizar política e socialmente sua ascensão econômica. Dessa luta nasceram os direitos civis e políticos que contemplavam seus anseios por liberdade de ir e vir, de expressão, de troca e de iniciativa econômica para conformação da economia de mercado, ou seja, direitos que acabavam por limitar a intervenção do Estado na vida social (1).

A Revolução Burguesa foi palco para o nascimento dos direitos sociais, pois em favor do desenvolvimento econômico sacrificou a classe trabalhadora e aqueles que se encontravam à margem da sociedade, gerando inconformismo e fazendo com que surgisse a necessidade de intervenção do Estado para que se alcançasse justiça social (1).

O progresso econômico e social, as lutas de classe do proletariado, a quebra da Bolsa de Nova York em 1929, o crescimento do socialismo soviético e do pensamento marxista de luta de classes fez surgir a "questão social" (7).

Houve um redimensionamento do papel do Estado, que passou a exercer um papel prestacional - serviços de saúde, educação, assistência social, etc - e de regulação direta dos mercados. 
No pós $2^{\mathrm{a}}$ Grande Guerra houve uma alteração do padrão de proteção social balizado pelo conceito de Welfare State - Estado de Bem Estar Social. Os governos foram responsabilizados pela garantia de um mínimo de proteção social (1).

No Brasil, entre os anos de 1970 e 1980, pós regime de ditadura militar, em um movimento pela redemocratização do país, os movimentos sociais ampliaram-se, propondo a democratização da saúde, do Estado e da sociedade, sob o lema da 'democratização da saúde'. Este movimento ficou conhecido como "Reforma Sanitária" (8).

As modificações necessárias ao setor saúde transcendem os limites de uma reforma administrativa e financeira, exigindo-se uma reformulação mais profunda, ampliando-se o próprio conceito de saúde e sua correspondente ação institucional, revendo- se a legislação no que diz respeito à promoção, proteção e recuperação da saúde, constituindo-se no que está se convencionando chamar de Reforma Sanitária (9).

A forte atuação do Movimento de Reforma Sanitária ensejou o surgimento de um discurso em defesa do direito universal à saúde e do dever do Estado em garanti-lo. Esse movimento, na VIII Conferência Nacional de Saúde, em 1986, produziu documento enviado à Comissão Nacional de Reforma Sanitária que influenciou a elaboração da nova Constituição Federal de 1988.

As novas bases da saúde lançadas pela Constituição de 1988 foram um momento muito importante para o desenvolvimento da saúde brasileira pois trazia a ampliação do conceito de saúde; a garantia da saúde como direito de cidadania e dever do Estado; e a instituição de um Sistema Único de Saúde (2).

Apesar de o sistema público de saúde do Brasil ter alcançado patamares de excelência ao longo dos anos, algumas dificuldades persistem, principalmente de acesso a serviços de média e alta complexidade e medicamentos.

\section{Judicialização da saúde}

A avaliação judicial das políticas públicas não é novidade no Brasil, contudo a participação do Poder Judiciário no processo de formulação e execução das políticas públicas é um fenômeno inédito. 
O controle judicial das políticas públicas ainda tem como obstáculo sua exteriorização distante de um padrão jurídico uniforme e claramente compreensível pelo sistema jurídico. E, além disto, é preciso lembrar que as políticas públicas são o reflexo de governos e condições políticas que mudam ao longo do tempo (10).

Política pública é o programa de ação governamental que resulta de um processo ou conjunto de processos juridicamente regulados - processo eleitoral, processo de planejamento, processo de governo, processo orçamentário, processo legislativo, processo administrativo, processo judicial - visando coordenar os meios à disposição do Estado e as atividades privadas, para a realização de objetivos socialmente relevantes e politicamente determinados (10).

A judicialização das políticas de saúde representa não apenas um conflito, mas também um fenômeno político-social (11). Ao realizar um mapeamento das condições políticas favoráveis ao surgimento do fenômeno da expansão do poder judicial no Brasil percebe-se que quase todas as condições favoráveis a esse fenômeno estão presentes: um Estado Democrático; a existência de direitos políticos formalmente reconhecidos por uma Constituição; grupos de interesses com boa parcela de participação nas ações judiciais; inefetividade das instituições majoritárias, ou seja, a incapacidade dessas instituições em dar provimento às demandas sociais. "O processo de judicialização da política no Brasil tem sido o resultado de uma progressiva apropriação das inovações da Constituição de 88 por parte da sociedade e de agentes institucionais" (11).

A 'judicialização da política' equivale-se à "politização da justiça", ou seja, é a expansão do Poder Judiciário no processo decisório das democracias contemporâneas (12). Para estes autores existem dois tipos de judicialização: 1) a reação do Judiciário à provocação de terceiro e que tem por finalidade revisar a decisão de um poder político tomando como base a Constituição e; 2) a utilização do aparato judicial na administração pública.

A judicialização das relações sociais se dá em um contexto em que o social, na ausência de Estado, das ideologias, da religião, se une ao direito com o objetivo de pleitear os anseios democráticos. "A justiça se torna um lugar em que se exige a realização da democracia" (12). 


\section{Metodologia}

Trata-se de uma revisão de literatura, realizada em banco de dados de produção acadêmica em saúde, dispostas na internet, e acesso livre, sobre o tema "judicialização da saúde".

Como marco temporal, delimitou-se a pesquisa entre os anos de 2010 e 2014. Os descritores utilizados foram: judicialização e saúde. Foram utilizados os marcadores booleanos a fim de poder aumentar a base de informação e a captura do máximo possível de trabalhos indexados. Os bancos de dados pesquisados foram a Biblioteca Virtual em Saúde (BVS), disponível na URL (www.bireme.br) e Scielo (www.scielo.org).

Foram incluídos nesta análise os trabalhos que discutem o fenômeno da judicialização da saúde. Embora os descritores utilizados, os trabalhos sobre bioética e saúde suplementar foram excluídos porque fugirem completamente ao tema.

Após a identificação dos artigos, teses e dissertações que atenderam aos critérios da pesquisa, os dados foram sistematizados em planilha a fim de gerar resultados.

\section{Resultados e discussão}

A pesquisa encontrou um universo de 35 produções acadêmicas, sendo 16 sobre a judicialização de medicamentos (Assistência Farmacêutica) e 14 sobre o fenômeno da judicialização o que vem corroborar a hipótese de que a produção acadêmica sobre judicialização da saúde no Brasil discute, principalmente, acesso a medicamentos via decisão judicial porque esse tem sido o principal objeto de judicialização no país. 
Figura 1 - Percentuais da produção acadêmica no Brasil sobre judicialização da saúde.

\section{Percentuais das produções acadêmicas no Brasil sobre "judicialização da saúde"}

- Assistência Farmacêutica Judicialização

Fonte: BVS e Scielo

A produção acadêmica no Brasil tem se dedicado ao estudo do fenômeno da judicialização do direito à saúde, enquanto direito fundamental social constitucionalizado, por meio de duas correntes de pensamento distintas: uma que vê no ativismo político do judiciário um empecilho para a efetivação do direito à saúde, enquanto direito coletivo, e outra, que atribui a este fenômeno uma forma de ampliação da cidadania e fortalecimento da democracia.

As produções acadêmicas analisadas foram organizadas em dois quadros para demonstrar o resultado da nossa coleta de dados e tornar claro quais textos e seus respectivos autores foram utilizados.

Quadro 1 - Textos que tratam da judicialização da assistência farmacêutica entre 2010 e 2014.

\begin{tabular}{|l|l|}
\hline \multicolumn{1}{|c|}{ Autores } & \multicolumn{1}{|c|}{ Títulos } \\
\hline Borges, D. C. L; Ugá, M. A. D. & $\begin{array}{l}\text { Conflitos e impasses da judicialização na obtenção de } \\
\text { medicamentos: as decisões de 1ā instância nas ações } \\
\text { individuais contra o Estado do Rio de Janeiro, Brasil, } \\
\text { em 2005. }\end{array}$ \\
\hline $\begin{array}{l}\text { Pepe, V. L. E; Figueiredo, T. A; Osorio- } \\
\text { de-Castro, L. S; Serpa, C. G; Ventura, } \\
\text { M. }\end{array}$ & $\begin{array}{l}\text { A judicialização da saúde e os novos desafios da } \\
\text { gestão da assistência farmacêutica }\end{array}$ \\
\hline Barcelos, P. C. & $\begin{array}{l}\text { Perfil de demandas judiciais de medicamentos da } \\
\text { Secretaria de Estado da Saúde do Espírito Santo: um }\end{array}$ \\
\hline
\end{tabular}




\begin{tabular}{|c|c|}
\hline & estudo exploratório \\
\hline $\begin{array}{l}\text { Machado, M. A. A.; Acurcio, F. A.; } \\
\text { Brandão, C. M. R; Faleiros, D. R; Guerra } \\
\text { Jr, A. A; Cherchiglia, M. L; Andrade, E. } \\
\text { L.G. }\end{array}$ & $\begin{array}{l}\text { Judicialização do acesso a medicamentos no Estado de } \\
\text { Minas Gerais, Brasil. }\end{array}$ \\
\hline $\begin{array}{l}\text { Sant'Ana, J. M. B; Pepe, V. L. E; Osorio- } \\
\text { de-Castro, C. G. S; Ventura, M. }\end{array}$ & $\begin{array}{l}\text { Essencialidade e assistência farmacêutica: } \\
\text { considerações sobre o acesso a medicamentos } \\
\text { mediante ações judiciais no Brasil. }\end{array}$ \\
\hline Silva, R. T. B. & $\begin{array}{l}\text { Conflitos bioéticos decorrentes do acesso a } \\
\text { medicamentos órfãos no Brasil: o exemplo da } \\
\text { laronidase para o tratamento da mucopolissacaridose } \\
\text { tipo I }\end{array}$ \\
\hline Diniz, D; Medeiros, M; Schwartz, I. V. D. & $\begin{array}{l}\text { Consequências da judicialização das políticas de } \\
\text { saúde: custos de medicamentos para as } \\
\text { mucopolissacaridoses }\end{array}$ \\
\hline $\begin{array}{l}\text { Campos Neto, O. H; Acurcio, F. A; } \\
\text { Machado, M. A. A; Ferré, F; Barbosa, F. } \\
\text { L. V; Cherchiglia, M. L; Andrade, E. L. G. }\end{array}$ & $\begin{array}{l}\text { Médicos, advogados e indústria farmacêutica na } \\
\text { judicialização da saúde em Minas Gerais, Brasil. }\end{array}$ \\
\hline $\begin{array}{l}\text { Pandolfo, M; Delduque, M C; Amaral, R } \\
\text { G. }\end{array}$ & $\begin{array}{l}\text { Aspectos jurídicos e sanitários condicionantes para o } \\
\text { uso da via judicial no acesso aos medicamentos no } \\
\text { Brasil. }\end{array}$ \\
\hline $\begin{array}{l}\text { Sartori Junior, D; Leivas, P. G. C; } \\
\text { Souza, M. V; Krug, B. C; Balbinotto, G; } \\
\text { Schwartz, I. V. D. }\end{array}$ & $\begin{array}{l}\text { Judicialização do acesso ao tratamento de doenças } \\
\text { genéticas raras: a doença de Fabry no Rio Grande do } \\
\text { Sul. }\end{array}$ \\
\hline Stamford, A; Cavalcanti, M. & $\begin{array}{l}\text { A Judicialização da Assistência Farmacêutica: o caso } \\
\text { Pernambuco em } 2009 \text { e } 2010 .\end{array}$ \\
\hline Barreira, S. C. F. & $\begin{array}{l}\text { Direito à saúde e judicialização de medicamentos: a } \\
\text { experiência de Niterói. }\end{array}$ \\
\hline Soares, J. C. R. S; Deprá, A. S. & $\begin{array}{l}\text { Ligações perigosas: indústria farmacêutica, } \\
\text { associações de pacientes e as batalhas judiciais por } \\
\text { acesso a medicamentos. }\end{array}$ \\
\hline Medeiros, M; Diniz, D; Schwartz, I. V. D. & $\begin{array}{l}\text { A tese da judicialização da saúde pelas elites: os } \\
\text { medicamentos para mucopolissacaridose. }\end{array}$ \\
\hline Carvalho, M. N; Leite, S. N. & $\begin{array}{l}\text { Itinerário dos usuários de medicamentos via judicial no } \\
\text { estado do Amazonas, Brasil. }\end{array}$ \\
\hline Guimarães, R. & $\begin{array}{l}\text { Incorporação tecnológica no SUS: o problema e seus } \\
\text { desafios. }\end{array}$ \\
\hline
\end{tabular}

Fonte: BVS e Scielo

Esta produção acadêmica aponta falhas do Sistema Público de Saúde e de sua gestão, uma vez que há solicitações de medicamentos constantes das listas oficiais da União, Estados e Municípios. Estas considerações estão presentes em produções acadêmicas dos Estados do Rio de Janeiro (13), Minas Gerais (14), Amazonas (15) e 
Espírito Santo (16), além do município de Niterói (17) o que nos leva a perceber certa capilaridade desta realidade.

Borges (13) e Barreira (17), em seus estudos no Estado do Rio de Janeiro e no Município de Niterói perceberam que a judicialização de medicamentos se dá devido o desabastecimento da Rede de Saúde por falhas do órgão competente dos Poderes Executivo Estadual e Municipal na efetivação da Política de Assistência Farmacêutica.

Em uma realidade completamente diferente em questões geográficas e socioeconômicas - Estado do Amazonas - Carvalho (15) percebeu a mesma relação de causa e efeito entre a má gestão da Política de Assistência Farmacêutica pelo Poder Executivo local e a judicialização de medicamentos.

Para Borges (13) e Barcelos (16) o fenômeno da judicialização da saúde pode ser considerado uma afronta ao princípio da separação dos poderes, porque por meio de decisões judiciais, o Poder Judiciário vem ditando a direção de Políticas Públicas de Saúde e a execução de orçamento público, invadindo, assim a competência privativa dos Poderes Executivo e Legislativo.

Apesar de reconhecer a legitimidade do Poder Judiciário para intervenção em decisões da Administração e do Poder Legislativo certos limites são necessários a tal intervenção, sob pena de ocorrer violação do princípio da separação de poderes, já que decisões sobre o fornecimento de medicamentos são decisões sobre alocação de recursos, com teor nitidamente discricionário e político e, portanto, tocam originalmente ao Poder Legislativo e Executivo.

Guimarães (18) ao estudar o tema da incorporação tecnológica no SUS constatou que a judicialização é resultado de pressões para que o SUS incorpore tecnologias e que a postura predominante hoje, no judiciário brasileiro, pode ferir o princípio da equidade ao avaliar de modo inadequado o princípio da integralidade.

Wang et al (19) em seu trabalho sobre a judicialização no Estado de São Paulo demonstrou que a judicialização acaba por produzir: acesso desigual ao SUS, favorecendo aqueles que acionam o Judiciário; desequilíbrio na distribuição de competências dentro do sistema, que potencialmente sobrecarrega o Município; e dificuldades para o planejamento e a gestão do orçamento público dada a imprevisibilidade do gasto imposto pelas ações judiciais. 
Para Pandolfo et al (20) o que mais chama atenção na análise dos processos judiciais de medicamentos é o elevado grau de sucesso dessas solicitações. Além disto, Borges (13), Barcelos (16), Machado (14) e Sartori (21) apontam ainda, que o Poder Judiciário tem decidido a favor do autor, sem que o tratamento solicitado tenha eficácia e segurança estabelecidas. Estes autores consideram isto um obstáculo para a prática do uso racional de medicamentos e a consolidação das premissas da Política Nacional de Medicamentos.

Sobre a judicialização de medicamentos para tratamento de doenças raras, Sartori et al (21) e Diniz et al (22) afirmam que este fenômeno decorre da ausência de uma Política do Sistema Público de Saúde para doenças raras, que padronize o acesso aos tratamentos. É importante lembrar que a Política Nacional de Atenção às Pessoas com Doenças Raras² instituída apenas no ano de 2014.

Para Silva (23) a grande quantidade de demandas judiciais, deste tipo de medicamento nos impõe a refletir sobre a necessidade de políticas que contemplem a necessidade de minorias, como os portadores de doenças raras, e a crescente preocupação com o financiamento público de medicamentos órfãos.

Campos (24) e Soares (25) nos trazem outras reflexões quando nos apresentam questionamentos sobre o papel da Medicina e dos advogados particulares e a relação entre Associações de portadores de doenças e o setor farmacêutico neste fenômeno da judicialização. Para Campos (24) a associação entre médicos e escritórios de advocacia nas solicitações dos medicamentos pode ser um indício de que a Justiça e a Medicina têm sido utilizadas para atender aos interesses da indústria farmacêutica. E para Soares (25) faz-se necessário aprofundar os conhecimentos sobre as relações existentes entre o setor farmacêutico e as associações representativas de portadores de doenças porque esta relação, em sua opinião, pode agravar o panorama da saúde brasileira, em relação ao uso crítico e responsável dos medicamentos.

Sant'Ana et al (26), Carvalho (15) e Pepe et al (27) vem apontar estratégias para avançarmos na resolução deste caos que se tornou a judicialização de medicamentos no Brasil: melhorar a interlocução entre o Poder Executivo e o Judiciário, partindo do

\footnotetext{
2 Portaria no 199, de 30 de janeiro de 2014 que Institui a Política Nacional de Atenção Integral às Pessoas com Doenças Raras, aprova as Diretrizes para Atenção Integral às Pessoas com Doenças Raras no âmbito do Sistema Único de Saúde (SUS) e institui incentivos financeiros de custeio.
} 
reconhecimento mútuo de suas insuficiências, limitações e responsabilidades e a sistematização das informações sobre as demandas judiciais.

Travassos (28) corrobora afirmando que o impacto destas decisões deve ser melhor analisado e compreendido pelos dois lados envolvidos no processo, o Poder Judiciário e os Serviços Públicos de saúde como forma de não provocar maiores iniquidades no sistema.

Barroso (29) faz principalmente, duas críticas ao que ele chamou de "judicialização excessiva" de medicamentos A primeira crítica se apoia na norma constitucional que estabelece que a garantia do direito à saúde se dará por meio de políticas sociais e econômicas e não por meio de decisões judiciais. E a segunda crítica levanta a discussão sobre a "legitimidade democrática" destas ações já que caberia apenas ao povo ou por meio de seus representantes eleitos a prerrogativa de decidir como gastar os recursos públicos.

Por outro lado, alguns autores veem na judicialização, o instrumento legítimo e eficaz para a efetivação do direito à saúde, universal e integral, previsto na Constituição. Ventura et al (30) afirma que as demandas judiciais podem ser admitidas como um elemento importante na tomada de decisão dos gestores e, muitas vezes, na melhoria do acesso aos medicamentos no âmbito do SUS. No contexto democrático brasileiro, a judicialização pode expressar reivindicações e modos de atuação legítimos de cidadãos e de instituições.

Quadro 2 - Textos que tratam do fenômeno da judicialização entre 2010 e 2014

\begin{tabular}{|l|l|}
\hline \multicolumn{1}{|c|}{ Autores } & \multicolumn{1}{|c|}{ Títulos } \\
\hline Machado, F. R.S. & $\begin{array}{l}\text { A judicialização da saúde no Brasil: cidadanias e } \\
\text { assimetrias. }\end{array}$ \\
\hline Valle, G. H. M; Camargo, J. M. P. & $\begin{array}{l}\text { A audiência pública sobre a judicialização da saúde e } \\
\text { seus reflexos na jurisprudência do Supremo Tribunal } \\
\text { Federal }\end{array}$ \\
\hline $\begin{array}{l}\text { Ventura, M; Simas, L; Pepe, V. L. E; } \\
\text { Schramm, F. R. }\end{array}$ & $\begin{array}{l}\text { Judicialização da saúde, acesso à justiça e a } \\
\text { efetividade do direito à saúde. }\end{array}$ \\
\hline Asensi, F. D. & $\begin{array}{l}\text { Judicialização ou juridicização? As instituições jurídicas } \\
\text { e suas estratégias na saúde }\end{array}$ \\
\hline Machado, F. R. S; Dain, S. & A Audiência Pública da Saúde: questões para a \\
\hline
\end{tabular}




\begin{tabular}{|l|l|}
\hline & judicialização e para a gestão de saúde no Brasil \\
\hline Travassos, D. V. & $\begin{array}{l}\text { Judicialização da saúde e Sistema Único de Saúde: } \\
\text { estudo de casos de três tribunais estaduais }\end{array}$ \\
\hline Asensi, F. D. & $\begin{array}{l}\text { Saúde, Poder Judiciário e sociedade: uma análise de } \\
\text { Brasil e Portugal. }\end{array}$ \\
\hline Carvalho, E. C; David, H. M. S. L. & $\begin{array}{l}\text { Judicialização da saúde, problema e solução: questões } \\
\text { para a enfermagem. }\end{array}$ \\
\hline $\begin{array}{l}\text { Gomes, F. F. C; Cherchiglia, M. L; } \\
\text { Machado, C. D; Santos, V. C; Acurcio, F. } \\
\text { A; Andrade, E. L. G. }\end{array}$ & $\begin{array}{l}\text { Acesso aos procedimentos de media e alta } \\
\text { complexidade no Sistema Único de Saúde: uma } \\
\text { questão de judicialização }\end{array}$ \\
\hline Diniz, D; Machado, T. R. C; Penalva, J. & A judicialização da saúde no Distrito Federal, Brasil. \\
\hline Machado, T. R. C. & $\begin{array}{l}\text { Judicialização da saúde: analisando a audiência pública } \\
\text { no Supremo Tribunal Federal }\end{array}$ \\
\hline $\begin{array}{l}\text { Aith, F; Bujdoso, Y; Nascimento, P. R; } \\
\text { Dallari, S. G. }\end{array}$ & $\begin{array}{l}\text { Os princípios da universalidade e integralidade do SUS } \\
\text { sob a perspectiva da política de doenças raras e da } \\
\text { incorporação tecnológica }\end{array}$ \\
\hline $\begin{array}{l}\text { Gomes, D. F; Souza, C. R; Silva, F. L; } \\
\text { Pôrto, J. A; Morais, I. A; Ramos, M. C; } \\
\text { Silva, E. N. }\end{array}$ & $\begin{array}{l}\text { Judicialização da saúde e a audiência pública } \\
\text { convocada pelo Supremo Tribunal Federal em 2009: o } \\
\text { que mudou de lá para cá? }\end{array}$ \\
\hline $\begin{array}{l}\text { Wang, D. W; Vasconcelos, N. P; Oliveira, } \\
\text { V. E; Terrazas, F. V. }\end{array}$ & $\begin{array}{l}\text { Os impactos da judicialização da saúde no município de } \\
\text { São Paulo: gasto público e organização federativa }\end{array}$ \\
\hline
\end{tabular}

Fonte: Scielo e BVS

Para Machado (31), por exemplo, a judicialização não é a causa do atual quadro em que se encontra a saúde pública brasileira e sim um resultado. Considera que a judicialização é um efeito da democracia e por isso, discutir a limitação da judicialização pode significar uma limitação da própria democracia.

Este autor afirma ainda, que a judicialização deveria ser tratada mais como um indicador das condições de saúde, do que como um problema em si mesmo. Este fenômeno está indicando que o investimento no setor saúde tem sido incapaz de atender às demandas de toda a população.

A judicialização pode, portanto, ser aliada do SUS, por sinalizar as deficiências e estimular a reflexão para novas políticas, de forma a reduzir a distância entre o SUS estabelecido no arcabouço normativo e o SUS que executa as ações e serviços de saúde. (32)

Para Aith et al (33) a judicialização da saúde é, e sempre será, uma importante via de acesso a serviços e produtos que ainda não estão incorporados ao sistema público de saúde. Para aqueles que apresentam necessidades diferenciadas a judicialização é 
uma importante estratégia, não apenas de alcançar sua demanda individual de saúde, mas de dar visibilidade a estas demandas e acelerar a incorporação de novas tecnologias.

Nesta mesma linha de raciocínio Fleury (34) acredita que a judicialização é fruto do aumento da democratização e inclusão social, mas também é fruto das deficiências do Legislativo, em manter a indefinição do arcabouço legal, e do Executivo, em sua incapacidade de executar o que já está posto legalmente. Esta autora acredita que a judicialização possa ser aliada do SUS, por sinalizar as deficiências e estimular a reflexão para novas políticas.

Bucci (10) corrobora esta opinião afirmando que a principal função do Poder Judiciário brasileiro no contexto político do século XXI será a de permitir a efetiva participação de grupos e segmentos da sociedade que não tem acesso ao poder político.

Asensi (35) reforça que o direito a saúde é um direito vivo e que em função de sua heterogeneidade e dinamicidade, revela as contradições fundamentais da relação entre Estado e sociedade civil. Considera válida a solicitação deste direito por via judicial, mas afirma que o Judiciário pode se apresentar somente como mais um desses atores.

Medeiros (36) e Diniz (37) trouxeram outro olhar sobre a judicialização, ao analisar a tese de que a judicialização reflete a elitização do processo judicial e de que há a prevalência de requisições de medicamentos de alto custo. Ambas as hipóteses não foram ratificadas em seus respectivos estudos. Segundo estes autores a afirmação de elitização não pode ser sustentada em todos os estados brasileiros e o objeto majoritário de pedidos são internações em unidades de tratamento intensivo, o que não corrobora a afirmação de que há prevalência de requisições de medicamentos de alto custo.

Valle (38), Machado (39), Machado (40) e Gomes (41) estudaram sobre a Audiência Pública n.4/2009, convocada pelo Ministro Gilmar Mendes para discutir a judicialização da saúde. Para estes autores não é o caso de apontar uma posição vencedora. A Audiência Pública veio reforçar a garantia de que o direito à saúde pode ser demandado judicialmente. No entanto, apesar das falhas na execução das políticas públicas a judicialização deve ser vista como um instrumento excepcional, não como regra do sistema. 


\section{Considerações finais}

Os resultados levam a concluir que a produção acadêmica sobre o tema da judicialização da saúde no Brasil volta-se em sua maioridade para a temática da judicialização de medicamentos.

Há uma corrente de autores que defendem que a principal causa para o aumento dos números de processos judiciais solicitando medicamentos são as falhas do Sistema Público de Saúde. A judicialização é vista como resultado de má gestão e execução de Políticas Públicas.

Outra corrente, afirma que a judicialização reflete a quebra do princípio da separação dos poderes porque ao decidir sobre a compra de medicamento ou oferta de um serviço o Judiciário decide sobre a execução de orçamento público, que vai causar consequência em todo o processo de planejamento e construção das Políticas Públicas de Saúde.

A produção acadêmica que discute o fenômeno da judicialização teoricamente afirma que $o$ ato de reivindicar por via judicial ações e serviços de saúde é resultado do modelo de Estado Democrático e deve ser considerado instrumento legítimo para a efetivação do direito à saúde, conforme previsto na Constituição. Neste sentido a judicialização é aliada do SUS, por sinalizar as deficiências e estimular a reflexão para novas políticas, além de instrumento que reforça o Estado Democrático em que vivemos porque viabiliza a grupos minoritários e vulneráveis o devido acesso à saúde.

A produção acadêmica no Brasil estuda o fenômeno da judicialização da saúde de forma polarizada, como era de se esperar de discussões científicas, em que a hegemonia não prevalece. De um lado, há o entendimento de que este fenômeno é um empecilho para a efetivação do direito à saúde, enquanto direito coletivo, e de outro entende-se que este fenômeno é uma forma de ampliação da cidadania e fortalecimento da democracia.

Há a necessidade de se fomentar pesquisas sobre a judicialização, a fim de se quebrar esta visão polarizada que se tem sobre o tema, avançando, assim, em um caminho de produção de um saber-fazer interdisciplinar e integrado. 


\section{Referências}

1 Figueiredo M F. Direito Fundamental à Saúde: Parâmetros para sua Eficácia e Efetividade. Porto Alegre: Editora Livraria do Advogado; 2007.

2 Brasil. Constituição da República Federativa do Brasil de 1988. Brasília: Senado Federal; 2015.

3 Delduque M C, Marques S B, Ciarlini A. Judicialização das Políticas de Saúde no Brasil. In: Delduque M C; Alves S M C, Neto N D. (Org.). Direito sanitário em perspectiva 2013:181-218. Brasília: ESMPU: FIOCRUZ.

4 Scliar M. Do Mágico ao Social: Trajetória da saúde pública. São Paulo: Editora SENAC; 2002.

5 Dallari S G. Poderes Republicanos e a defesa do Direito à saúde. Evolução da proteção do Direito à saúde nas Constituições do Brasil. In: Delduque M C, Alves S M C, Neto N D (org.). Direito Sanitário em perspectiva. Brasília: ESMPU: FIOCRUZ; 2013:1741.

6 World Health Organization. Constitution of the World Health Organization. New York: 1946. [Acesso em 29 set 2015]. Disponível em:

http://apps.who.int/gb/DGNP/pdf files/constitution-en.pdf.

7 Lobato L V C. Políticas Sociais e de Saúde. Rio de Janeiro: CEBES; 2012.

8 Paim, J S. A Reforma Sanitária e o CEBES. Rio de Janeiro: CEBES; 2012.

9 Brasil. Relatório da VIII Conferência Nacional de Saúde. [Internet]1986. [Acesso em 4 out 2015]. Disponível em:

http://conselho.saude.gov.br/biblioteca/relatorios/relatorio 8.pdf

10 Bucci, M P D. O conceito de política pública em direito. In: Bucci, M P D (org.).

Políticas Públicas: reflexões sobre o conceito jurídico. São Paulo: Editora Saraiva; 2006:1-51.

11 Carvalho E. Em busca da judicialização da política no Brasil: apontamentos para uma nova abordagem. Curitiba: Revista de Sociologia Política. 2004 [Acesso em 4 out 2015]; 23:115-126. Disponível em: http://www.scielo.br/pdf/rsocp/n23/24626.pdf.

12 Werneck L V (et al). A judicialização da política e das relações sociais no Brasil. Rio de Janeiro: Revan;1999.

13 Borges D C L, Ugá M A D. Conflitos e impasses da judicialização na obtenção de medicamentos: as decisões de $1^{\underline{a}}$ instância nas ações individuais contra o Estado do Rio de Janeiro em 2005. Caderno Saude Publica. 2010 [Acesso em 05 out 2015]; 26 (1): 5969. Disponível em: http://pesquisa.bvs.br/brasil/resource/pt/lil-539224. 
14 Machado M A A, Acurcio F A, Brandão C M R, Faleiros D R, Guerra A A, Cherchiglia $M$ L, Andrade E G. Judicialização do acesso a medicamentos no Estado de Minas Gerais, Brasil. São Paulo: Rev.Saúde Pública 45 (3), 2011 [Acesso em 05 out 2015]; Disponível em: http://www.scielo.br/scielo.php?script=sci arttext\&pid=S0034$\underline{89102011000300018}$

15 Carvalho M N, Leite S N. Itinerário dos usuários de medicamentos via judicial no estado do Amazonas, Brasil. Interface (Botucatu), 18 (51): 737,2014 [Acesso em 14 nov 2015]; 748. Disponível em:

http://www.scielo.br/scielo.php?script=sci abstract\&pid=S141432832014000400737\&lng=pt\&nrm=iso\&tlng=pt

16 Barcelos P C. Perfil de demandas judiciais de medicamentos da Secretaria de Estado da saúde do Espírito Santo: um estudo exploratório. Caderno Saúde Pública 26 (1): 5969, 2010 [Acesso em 05 out 2015];: Disponível em:

http://pesquisa.bvs.br/brasil/resource/pt/lil-539224.

17 Barreira S C F. Direito à saúde e judicialização de medicamentos: a experiência de Niterói. 2012. Tese de Mestrado em Instituto de Medicina Social. Universidade do Estado do Rio de Janeiro, 2012.

18 Guimarães, R. Incorporação tecnológica no SUS: o problema e seus desafios. Ciência \& Saúde Coletiva 19(12):4899-4908,2014. [Acesso em 05 out 2015]. Disponível em: http://www.scielo.br/pdf/csc/v19n12/pt 1413-8123-csc-19-12-04899.pdf

19 Wang D W L, Vasconcelos N P, Oliveira V E, Terrazas F V. Os impactos da judicialização da saúde no município de São Paulo: gasto público e organização federativa. Rev. Administração Pública 48 (5), 2014 [Acesso em 31 out 2015]; Disponível

em:http://www.scielo.br/scielo.php?script=sci arttext\&pid=S003476122014000500006\&l ang $=\mathrm{pt}$

20 Pandolfo M, Delduque M C e Amaral R G. Aspectos jurídicos e sanitários condicionantes para o uso da via judicial no acesso aos medicamentos no Brasil. Revista Salud pública, 14 (2): 340-349, 2012 [Acesso em 05 out 2015]; . Disponível em: http://www.scielosp.org/scielo.php?pid=S0124-00642012000200014\&script=sci arttext

21 Sartori D, Leivas P G C, Souza M V, Krug B C, Balbinotto G, Schwartz I V D. Judicialização do acesso ao tratamento de doenças genéticas raras: a doença de Fabry no Rio Grande do Sul. Ciência Saúde Coletiva 17 (10), 2012 [Acesso em 14 nov 2015]. Disponível em: http://www.scielo.br/scielo.php?pid=S141381232012001000020\&script=sci arttext

22 Diniz D, Medeiros M, Schwartz I V D. Consequências da judicialização das políticas de saúde: custos de medicamentos para as mucopolissacaridoses. Caderno Saúde 
Pública. 28 (3), 2012 [Acesso em 14 nov 2015]. Disponível em:

http://www.scielo.br/scielo.php?script=sci arttext\&pid=S0102-311X2012000300008

23 Silva, Raquel Tavares Boy da Conflitos bioéticos decorrentes do acesso a medicamentos órfãos no Brasil: o exemplo da laronidase para o tratamento da mucopolissacaridose tipo I. 2011. Tese de doutorado Escola Nacional de Saúde Pública Sergio Arouca, 2011.

24 Campos O H, Acurcio F A, Machado M A A, Ferré F, Barbosa F L V, Cherchiglia M L, et al. Médicos, advogados e indústria farmacêutica na judicialização da saúde em Minas Gerais, Brasil. São Paulo: Revista Saúde Pública, 46 (5), 2012 [Acesso em 14 nov 2015]; Disponível em: http://www.scielo.br/scielo.php?script =sci_arttext\&pid=S0034-89102012000500004

25 Soares J C R S, Deprá A S. Ligações perigosas: indústria farmacêutica, associações de pacientes e as batalhas judiciais por acesso a medicamentos. Physis 22 (1), 2012 [Acesso em 14 nov 2015]. Disponível em: http://www.scielo.br/scielo.php?script=sci arttext\&pid=S0103-73312012000100017

26 Sant'Ana J M B, Pepe V L E, Osorio-de-Castro C G S, Ventura M. Essencialidade e assistência farmacêutica: considerações sobre o acesso a medicamentos mediante ações judiciais no Brasil. Revista Panam Salud Publica 29 (2), 2011 [Acesso em 14 nov 2015]; Disponível em: http://www.scielosp.org/scielo.php?script=sci arttext\&pid=S1020$\underline{49892011000200010}$

27 Pepe V L E, Figueiredo T A, Simas L, Osorio-de-Castro C G S, Ventura M. A judicialização da saúde e os novos desafios da gestão da assistência farmacêutica. Ciência saúde coletiva 15 (5), 2010 [Acesso em 14 nov 2015]; Disponível em: http://www.scielo.br/scielo.php?script=sci arttext\&pid=S1413-81232010000500015

28 Travassos, D V. Judicialização da saúde e Sistema Único de Saúde: estudo de casos de três tribunais estaduais [Tese]. Belo Horizonte: Programa de Pós Graduação da Faculdade de Odontologia da Universidade Federal de Minas Gerais; 2012. [Acesso em 14 nov 2015]. Disponível em: http://www.scielo.br/scielo.php?pid=S1413$81232013001100031 \&$ script=sci_arttext.

29 Barroso L R. Da falta de efetividade à judicialização excessiva: Direito à saúde, fornecimento gratuito de medicamentos e parâmetros para a atuação judicial. Revista Jurídica 1 (1), 1998 [Acesso em 04 out 2015]; Disponível em:

http://www.uniube.br/publicacoes/unijus/arquivos/unijus 15.pdf.

30 Ventura M, Simas L, Pepe V L E, Schramm F R. Judicialização da saúde, acesso à justiça e a efetividade do direito à saúde. Physis: Revista de Saúde Coletiva 20 (1),. 2010. [Acesso em 14 nov 2015]. Disponível em: http://www.scielo.br/scielo.php?pid=S0103-73312010000100006\&script=sci arttext 
31 Machado, F R S. A judicialização da saúde no Brasil: cidadanias e assimetrias. [Tese] [Internet]. Rio de Janeiro: Programa de Pós-Graduação em Saúde Coletiva do Estado do Rio de Janeiro; 2010. [Acesso em 14 nov 2015]. Disponível em: http://unisc.br/portal/upload/com_arquivo/1349808773.pdf

32 Gomes F F C, Cherchiglia M L, Machado C D, Santos V C, Acurcio F A, Andrade E L G. Acesso aos procedimentos de média e alta complexidade no Sistema Único de Saúde: uma questão de judicialização. Caderno Saúde Pública . 30 (1), 2014. [Acesso em 14 nov 2015]; Disponível em: http://www.scielo.br/scielo.php?pid=S0102$\underline{311 \times 2014000100031 \& s c r i p t=s c i}$ arttext

33 Aith F, Bujdoso Y, Nascimento P R, Dallari S G. Os princípios da universalidade e integralidade do SUS sob a perspectiva da política de doenças raras e da incorporação tecnológica. Revista de Direito Sanitário,15 (1), 2014. [Acesso em 14 nov 2015] .Disponível em: http://www.revistas.usp.br/rdisan/article/view/82804.

34 Fleury S. Judicialização pode salvar o SUS. Revista Saúde em Debate 36 ( 93):15916, 2012 [Acesso em 31 out 2015]. 2. Disponível em:

http://peep.ebape.fgv.br/sites/peep.ebape.fgv.br/files/A judicializacao pode salvar o S US Saude em Debate.pdf

35 Asensi. Felipe Dutra Saúde, Poder Judiciário e sociedade: uma análise de Brasil e Portugal. Physis 23 (3), 2013 [Acesso em 11 nov 2015];. Disponível em: http://www.scielo.br/scielo.php?script=sci arttext\&pid=S0103-73312013000300008

36 Medeiros M, Diniz D, Schwartz I V. A tese da judicialização da saúde pelas elites: os medicamentos para mucopolissacaridose. Revista Ciência saúde coletiva 18 (4),2013 [Acesso em 15 nov 2015]; Disponível em: http://www.scielo.br/scielo.php?script=sci arttext\&pid=S1413-81232013000400022

37 Diniz D, Machado T R C, Penalva J. A judicialização da saúde no Distrito Federal, Brasil. Revista Ciência saúde coletiva. 19 (2), 2014 [Acesso em 15 nov 2015]. Disponível em: http://www.scielo.br/scielo.php?pid=S1413-81232014000200591\&script=sci arttext

38 Valle G H M, Camargo J M P. A audiência pública sobre a judicialização da saúde e seus reflexos na jurisprudência do supremo tribunal federal. Revista de Direito Sanitário 11 (3), 2011 [Acesso em 15 nov 2015]. Disponível em: http://www.revistas.usp.br/rdisan/article/view/13220

39 Machado F R S, Dain S. A Audiência Pública da Saúde: questões para a judicialização e para a gestão de saúde no Brasil. Rev. Adm. Pública, 46 (4), 2012 [Acesso em 15 nov 2015]; Disponível em:

http://www.scielo.br/scielo.php?script=sci arttext\&pid=S0034-76122012000400006

40 Machado, T R C. Judicialização da saúde: analisando a audiência pública no Supremo Tribunal Federal. Rev. bioética.22 (3): 561-8, 2014 [Acesso em 15 nov 2015]. Disponível em: http://www.scielo.br/pdf/bioet/v22n3/v22n3a20.pdf 
41 Gomes Dalila F, Souza C R, Silva F L, Pôrto J A, Morais I A, Ramos M C, et al. Judicialização da saúde e a audiência pública convocada pelo Supremo Tribunal Federal em 2009: o que mudou de lá para cá? Saúde Debate 38 (100):139-156, 2014 [Acesso em 15 nov 2015]. Disponível em: http://www.scielo.br/pdf/sdeb/v38n100/01031104-sdeb-38-100-0139.pdf

\section{Como citar este artigo:}

Bittencourt GB. O "Estado da Arte" da produção acadêmica sobre o fenômeno da judicialização da saúde no Brasil. Revista Cadernos Ibero-Americanos de Direito Sanitário. 2016 jan./mar, 5(1):102-121. 